Thorax, 1979, 34, 783-788

\title{
Diet, absorption, and hormone studies in relation to body weight in obstructive airways disease
}

\author{
P d'A SEMPLE, ${ }^{1}$ W S WATSON, ${ }^{2}$ G H BEASTALL, ${ }^{4}$ M I F BETHEL, ${ }^{3}$ J K GRANT, ${ }^{4}$ \\ AND R HUME ${ }^{1}$
}

From the Division of Medicine, ${ }^{1}$ Department of Clinical Physics and Bioengineering, ${ }^{2}$ Dietetic Department, ${ }^{3}$ Southern General Hospital, Glasgow G51, and Department of Steroid Biochemistry, ${ }^{4}$ Royal Infirmary, Glasgow G4, UK

\begin{abstract}
Sixteen male patients with stable chronic obstructive airways disease were separated into two groups of eight according to arterial carbon dioxide tensions. Hypercapnia was associated with lower arterial oxygen tensions, higher red cell volume, and increased weight, while normocapnic subjects were decidedly thin. The considerable difference in body weight between the two groups could not be explained by variation in calorie intake, and malabsorption was excluded as a cause of weight loss in the underweight subjects. Serum tri-iodothyronine, thyroxine, cortisol, and oestradiol concentrations were similar and normal in each group, but both groups had significantly low testosterone values as compared with controls, values in the hypercapnic being appreciably lower than in the normocapnic group. The adrenal androgen dehydroepiandrosterone was significantly high in the normocapnic group and low in the hypercapnic group compared with controls. Serum pituitary luteinising and follicle stimulating hormones were normal, but three hypercapnic individuals had high serum prolactin values. Early morning urinary aldosterone values were significantly higher in the hypercapnic than in the normocapnic group. Such hormone comparisons have not previously been made in subjects with chronic obstructive airways disease grouped according to arterial blood gas values, and it is concluded that major alterations in adrenal and testicular function may occur, possibly due to pituitary suppression from hypoxia. Such hormonal changes might in part account for the contrasting alterations in body habitus found in this condition.
\end{abstract}

Whereas patients with chronic obstructive airways disease (COAD) who are chronic bronchitics tend to be overweight, those with predominant emphysema lose weight and tend to be thin (Vandenbergh et al, 1967; Campbell et al, 1975; Semple, 1978; Thurlbeck, 1978). Depressed food intake has already been shown to occur only in a proportion of these thin emphysematous subjects (Wilson et al, 1964; Vandenbergh et al, 1967). Malabsorption is a possible factor as this has been described in emphysema with alpha ${ }_{1}$-antitrypsin deficiency (Greenwald et al, 1975) and also in association with the weight loss of altitude hypoxia (Pugh, 1962) although in this condition appetite suppression does occur. A high prevalence of gastrointestinal disturbances in COAD has been cited as a possible cause of poor appetite (Vanderbergh et al, 1967), while yet another factor contributing to the weight loss may be the increased energy expenditure of dyspnoeic breathing (Cherniack, 1959). Depression of adrenal and gonadal function which occurs at altitude (Pugh, 1962; GuerraGarcia et al, 1969) could contribute to weight loss by reducing anabolic steroid hormone production, and a similar type of hormone depression has already been noted in emphysema (Marmorston et $a l, 1966)$. As the reasons for weight loss in emphysema are far from clear, we have sought to determine the relation of diet and absorption of food to body habitus in COAD and have also studied the hormonal aspects of two groups of patients with obstructive airways disease-hypercapnic, hypoxic chronic bronchitic "blue bloaters" and their thin emphysematous normocapnic "pink puffer" counterparts. 


\section{Methods}

Approval for the project was granted by the hospital ethical committee, and informed written consent obtained from all patients. Sixteen stable male chest clinic patients were chosen to represent a wide range of body habitus. All had grade 3 or 4 dyspnoea (MRC questionnaire on respiratory symptoms, 1966) and only one was a non-smoker. By spirometry (Vitalograph, sitting) forced expiratory volume in one second $\left(\mathrm{FEV}_{1}\right)$ was always less than $70 \%$ of predicted normal value and forced expiratory volume/forced vital capacity ratio $\left(\mathrm{FEV}_{1} / \mathrm{FVC} \%\right)$ was always less than $70 \%$, signifying airways obstruction. Patients were selected by the above criteria, and their blood gas tensions were then measured. They were grouped according to arterial carbon dioxide tensions $\left(\mathrm{PaCO}_{2}\right)$, those with a $\mathrm{PaCO}_{2}$ level greater than $5.8 \mathrm{kPa}$ hereafter being referred to as the "hypercapnic group" and those with a level less than $5.8 \mathrm{kPa}$ as the "normocapnic group."

Subjects were admitted to a metabolic unit for three days. Height and weight were measured, and the latter value was compared with that predicted for sex, age, and height (Society of Actuaries, Chicago, 1959). Arterial blood samples for blood gas estimation were taken from the radial artery, 흘 the subject having rested breathing room air for $\frac{\bar{s}}{7}$ 30 minutes. Red cell volume was performed byळ administering ${ }^{51} \mathrm{Cr}$ labelled red cells and measuring the radioactivity in samples 10,20 , and 30 minutes after injection. Predicted normal values were cal- culated using the equation developed by $\operatorname{Nadler} \vec{\omega}$ et al (1962) and modified by Hume and Goldbergo (1963).

Food consumption was assessed by experienced $\omega_{\perp}$ dieticians and converted to a caloric value (McCance and Widdowson, 1960), that was then compared with the individual's predicted normal $\omega$ value (DHSS Report No 120, HMSO 1969). Similar윽 dietary assessments for comparison were made in 18 men admitted with various traumatic ortho-

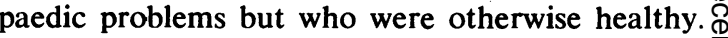
In addition the eight underweight subjects underwent jejunal biopsy, estimation of serum iron, $B_{12}$, 只 and folate as well as d-xylose excretion test and $\vec{\varphi}$ three-day faecal fat estimation to assess intestinal $\overparen{c}$ absorption.

Blood was taken at midday from patients on the second day of admission. Serum tri-iodothyronine $\left(\mathrm{T}_{3}\right)$, thyroxine $\left(\mathrm{T}_{4}\right), 17$ hydroxyandrogens (testosterone), dehydroepiandrosterone (DHA), lutein- $\frac{\circ}{\Phi}$ ising hormone $(\mathrm{LH})$, follicle stimulating hormone $\mathrm{a}$

Table 1 Laboratory results of patients with chronic obstructive airways disease grouped according to Paco: values

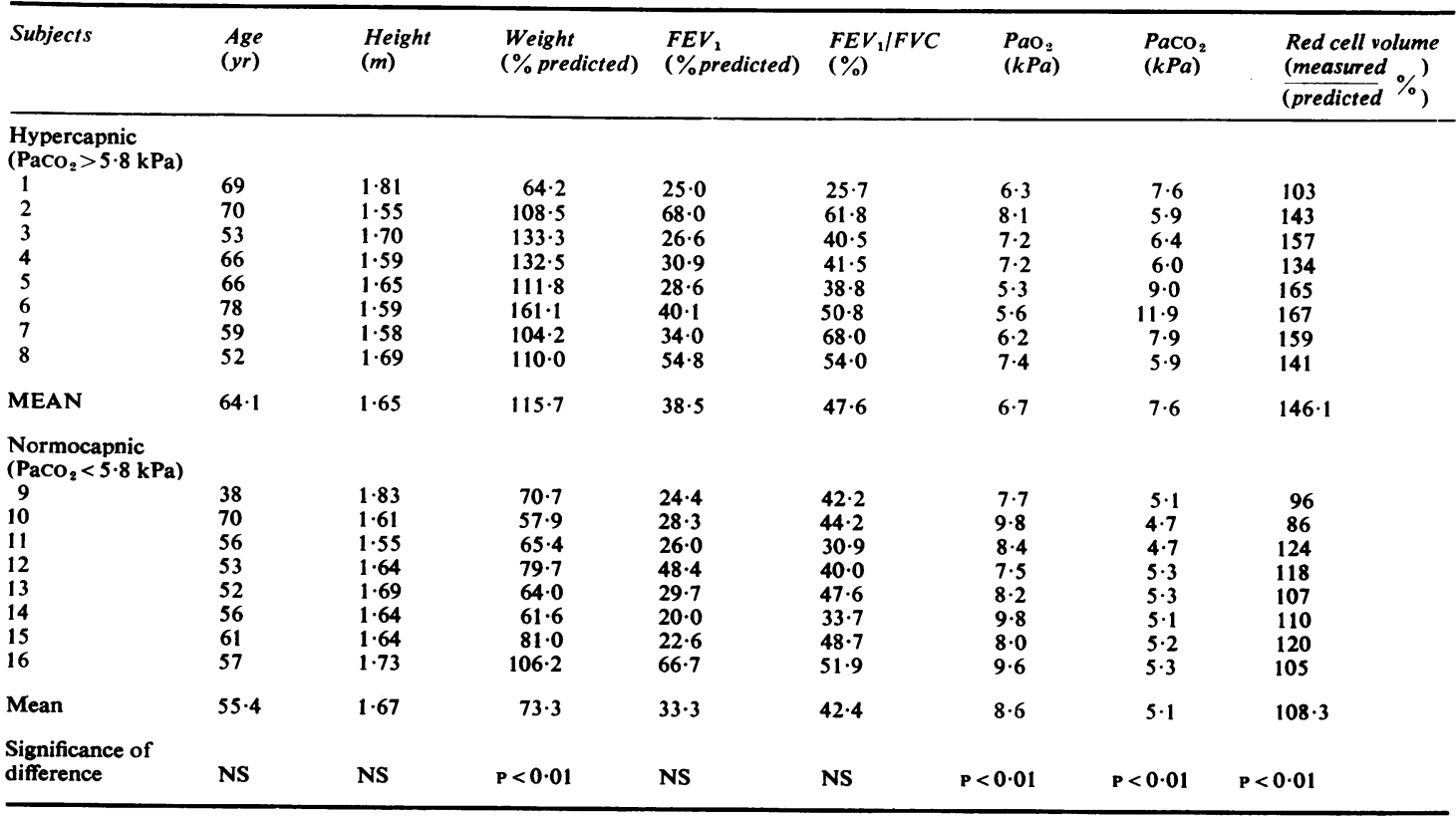

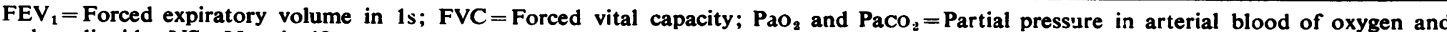
carbon dioxide; NS $=$ Not significant. 
(FSH), and prolactin as well as urinary aldosterone values were measured by radioimmunoassay and serum cortisol by a fluorimetric method.

Control values for these hormones were taken from a group of 14 male patients without chest disease matched for age attending either an anticoagulant clinic or with treated pernicious anaemia at a haematology clinic. Statistical comparisons were made with Wilcoxon's rank test.

\section{Results}

There was no significant difference in age, height, or spirometric readings between the two groups of subjects separated according to $\mathrm{PaCO}_{2}$ values (table 1), but the hypercapnic group of eight subjects was significantly heavier (hypercapnic mean weight $78.0 \mathrm{~kg}$; normocapnic $51.7 \mathrm{~kg}$; $\mathrm{P}<0.01$ ). Seven of the eight hypercapnic subjects were overweight and seven of the eight normocapnic subjects underweight. The hypercapnic group had lower arterial oxygen tensions and higher red cell volume expressed as a percentage of predicted normal.

Five of the overweight and seven of the underweight subjects ingested less than their predicted calorie requirement (table 2), and there was no significant difference between the two groups in mean daily calorie intake. On average both groups ingested more but not significantly more than the healthy men. Daily protein intake was normal and similar in each group as were the serum $T_{3}$ and $T_{4}$ values. The various investigations performed to exclude malabsorption in the eight underweight subjects produced normal results.

All but one of our 16 COAD subjects (No 1 had a modestly raised value) had normal values for serum cortisol (table 3). The hypercapnic group had a significantly lower mean testosterone level than the normocapnic group, and both study groups had significantly lower values than the control group. Seven of the eight hypercapnic and one of the eight normocapnic subjects had serum testosterone values below the lower limit of normal. Serum dehydroepiandrosterone was not significantly lower in the hypercapnic group than in controls but was higher in the normocapnic group than in controls. All individual values, however, were within the normal range except for subject 11 who had a raised value. Serum oestradiol, $\mathrm{LH}$, and FSH were similar and normal in both groups. Serum prolactin concentrations were higher in the hypercapnic group than in both normocapnic and control groups, although the differences were not significant. However, three individual hypercapnic subjects (4, 5, and 6) had raised values. Early morning urinary aldosterone levels were higher in the hypercapnic group as compared with the normocapnic group.

Table 2 Calorie and protein intake and thyroid function in patients with chronic obstructive airways disease grouped according to weight

\begin{tabular}{|c|c|c|c|c|c|c|c|}
\hline Subjects & $\begin{array}{l}\text { Weight } \\
(k g)\end{array}$ & $\begin{array}{l}\text { Weight } \\
\text { (\% predicted) }\end{array}$ & $\begin{array}{l}k \text { calories } \\
(\text { daily })\end{array}$ & $\begin{array}{l}k \text { calories } \\
(\% \text { predictea })\end{array}$ & $\begin{array}{l}\text { Protein } \\
\text { (g/day) }\end{array}$ & $\begin{array}{l}\text { Serum } T_{8} \\
(\text { nmol } / l)\end{array}$ & $\begin{array}{l}\text { Serum } T \\
(\text { nmolll })\end{array}$ \\
\hline $\begin{array}{c}\text { Overweight } \\
2 \\
3 \\
4 \\
5 \\
6 \\
7 \\
8 \\
16\end{array}$ & $\begin{array}{r}66 \cdot 9 \\
98 \cdot 0 \\
84 \cdot 4 \\
76 \cdot 0 \\
101 \cdot 1 \\
67 \cdot 7 \\
79 \cdot 6 \\
80 \cdot 0\end{array}$ & $\begin{array}{l}108 \cdot 5 \\
133 \cdot 3 \\
132 \cdot 5 \\
111 \cdot 8 \\
161 \cdot 1 \\
104 \cdot 2 \\
110 \cdot 0 \\
106 \cdot 2\end{array}$ & $\begin{array}{l}2409 \\
4682 \\
2304 \\
2746 \\
2108 \\
1759 \\
1799 \\
1388\end{array}$ & $\begin{array}{r}102 \cdot 5 \\
161 \cdot 5 \\
98 \cdot 0 \\
116 \cdot 9 \\
81 \cdot 1 \\
67 \cdot 7 \\
69 \cdot 2 \\
53 \cdot 4\end{array}$ & $\begin{array}{r}74 \\
118 \\
68 \\
59 \\
83 \\
53 \\
53 \\
44\end{array}$ & $\begin{array}{l}2 \cdot 0 \\
1 \cdot 6 \\
1 \cdot 8 \\
1 \cdot 7 \\
0 \cdot 9 \\
1 \cdot 8 \\
1 \cdot 9 \\
1 \cdot 3\end{array}$ & $\begin{array}{r}72 \\
74 \\
62 \\
72 \\
81 \\
91 \\
132 \\
51\end{array}$ \\
\hline Mean & $81 \cdot 7$ & $121 \cdot 0$ & 2399 & $93 \cdot 7$ & $69 \cdot 0$ & $1 \cdot 63$ & $79 \cdot 4$ \\
\hline $\begin{array}{l}\text { Underweight } \\
9 \\
10 \\
11 \\
12 \\
13 \\
14 \\
15 \\
1\end{array}$ & $\begin{array}{l}57 \cdot 4 \\
37 \cdot 8 \\
41 \cdot 2 \\
54 \cdot 6 \\
46 \cdot 3 \\
42 \cdot 2 \\
54 \cdot 4 \\
52 \cdot 6\end{array}$ & $\begin{array}{l}70 \cdot 7 \\
57 \cdot 9 \\
65 \cdot 4 \\
79 \cdot 7 \\
64 \cdot 0 \\
61 \cdot 6 \\
81 \cdot 0 \\
64 \cdot 2\end{array}$ & $\begin{array}{l}2864 \\
1434 \\
1854 \\
2304 \\
3214 \\
1939 \\
2231 \\
2081\end{array}$ & $\begin{array}{r}98 \cdot 8 \\
61 \cdot 0 \\
78 \cdot 9 \\
88 \cdot 6 \\
110 \cdot 8 \\
74 \cdot 6 \\
85 \cdot 8 \\
88 \cdot 6\end{array}$ & $\begin{array}{r}102 \\
54 \\
55 \\
47 \\
87 \\
73 \\
66 \\
67\end{array}$ & $\begin{array}{l}2 \cdot 1 \\
2 \cdot 1 \\
1 \cdot 7 \\
1 \cdot 8 \\
1 \cdot 7 \\
1 \cdot 6 \\
1 \cdot 6 \\
1 \cdot 6\end{array}$ & $\begin{array}{l}83 \\
90 \\
71 \\
74 \\
68 \\
89 \\
84 \\
80\end{array}$ \\
\hline Mean & $48 \cdot 3$ & $68 \cdot 1$ & 2240 & 85.9 & 68.9 & $1 \cdot 78$ & 79.9 \\
\hline $\begin{array}{l}\text { Significance of } \\
\text { difference* }\end{array}$ & $P<0.01$ & $P<0.01$ & NS & NS & NS & NS & NS \\
\hline $\begin{array}{r}\text { Controls-Mean } \\
\text { Range }\end{array}$ & & & $\begin{array}{l}2172 \\
1400-4460\end{array}$ & $\begin{array}{l}83 \cdot 5 \\
53 \cdot 8-171 \cdot 5\end{array}$ & $\begin{array}{l}70 \cdot 4 \\
53-96\end{array}$ & & \\
\hline
\end{tabular}

*Statistics using Wilcoxon's rank test.

$T_{3}=$ Tri-iodothyronine; $T_{4}=$ Thyroxine. 
Table 3 Results of hormone analyses in patients with chronic obstructive airways disease grouped according to $\mathrm{PaCO}_{2}$ values

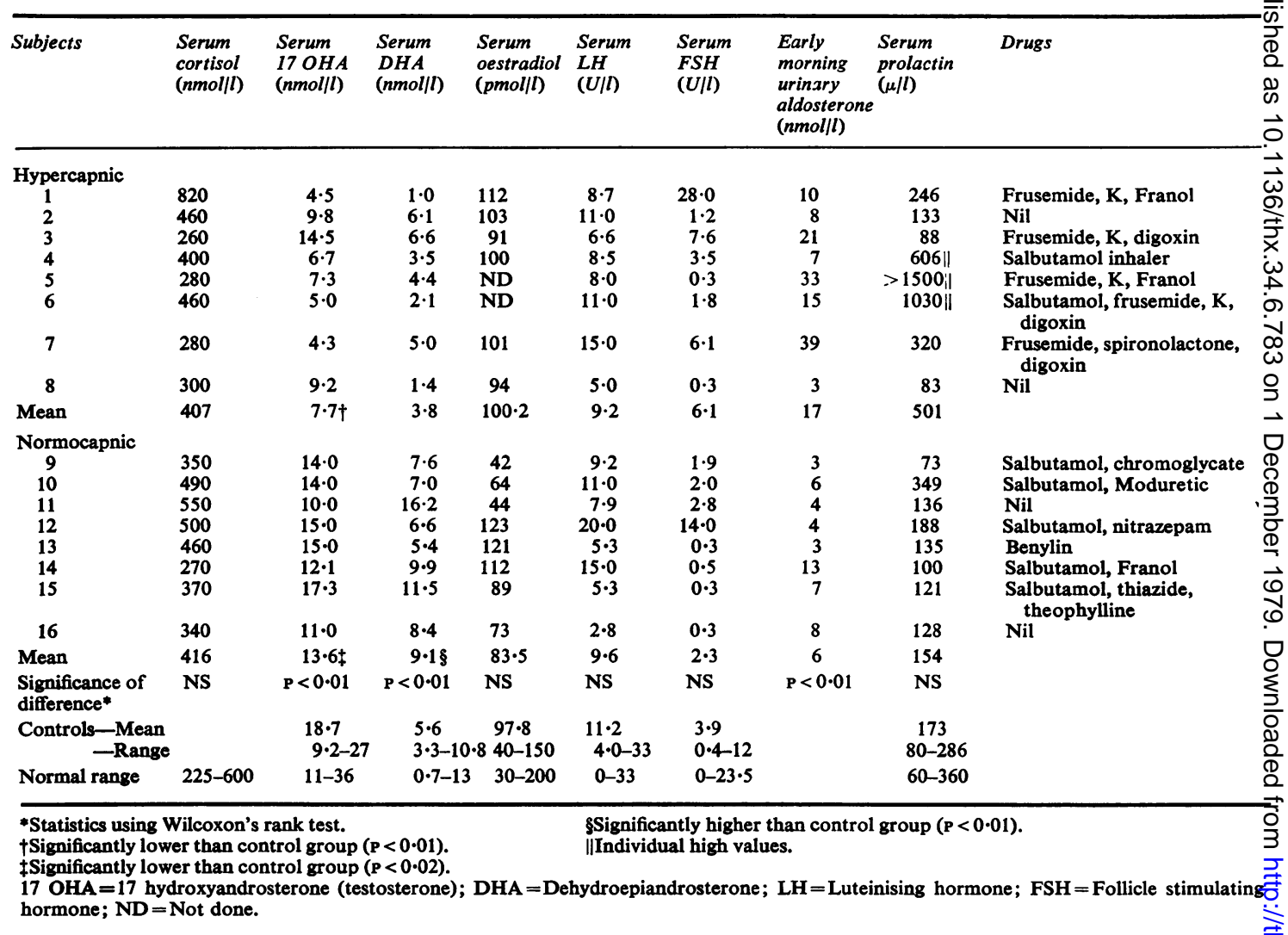

\section{Discussion}

Interestingly, patients with COAD and with hypercapnia were overweight while those with normocapnia were decidedly underweight. While this finding may not be universal it supports the clinical impression of two groups of patients at the ends of a range, the hypoxic, hypercapnic, polycythaemic, overweight blue bloaters and the underweight emphysematous pink puffers with near normal arterial blood gas tensions. This study makes some new observations on the metabolic and endocrine aspects of these two groups.

Although diets have previously been assessed in emphysematous subjects losing weight, the food intake of the two groups defined here have never been compared. Within the limitations of skilled dietary assessment our results suggest that while appetite suppression may be present in individual subjects with COAD this is not universal, and indeed neither group shows a consistent alteration in eating habits (table 2). Our patients, however, were comparatively well when interviewed, an possibly dietary suppression contributes to the rapid loss of lean body mass noted during exaces bations of COAD (Campbell et al, 1975). Twa previous studies (Wilson et al, 1964; Vandenbergh et al, 1967) showed a significant reduction in meap calorie intake in emphysematous subjects losin weight, but in both studies there was a wide range of calorie intake between individuals and indee some weight-losing subjects ate much more thaw other weight-stable subjects. This suggests somes other mechanism of weight loss; a view supportes by Campbell and colleagues (1975) who noted from published reports that hypoxia in human altitude tests and also in laboratory animal experiment causes loss of tissue mass by an as yet unexplaine\& process. From our investigation neither malabsorption nor abnormal thyroid function seem to bs causative factors. Another hypothetical cause of weight loss is increased calorie expenditure frores the work of breathing in emphysema (Cherniack 1959). Weight loss, however, may be very rapid in 
exacerbations of COAD (Campbell et al, 1975), yet the proportion of the metabolic rate contributed by the work of breathing is quite small.

Altitude hypoxia has been shown to depress adrenal and gonadal function (Pugh, 1962; GuerraGarcia et al, 1969), and Marmorston et al (1966) have drawn attention to abnormal urinary hormonal excretion patterns in emphysema. Although each of these conditions is associated with weight loss (Pugh, 1962; Campbell et al, 1975), apparently these two aspects, hormonal and metabolic, have not before been causally linked. In our study serum testosterone values were significantly low in both groups but considerably so in the hypercapnic overweight group where seven of the eight subjects had individually low values. We do not feel that age differences account for this, as appreciable reduction in testosterone does not occur till after the age of 70 (Stearns et al, 1974). It is known that low testosterone values in men may cause obesity in addition to impotence, female distribution of fat and hair, and soft small testes (Franks et al, 1978). Possibly, therefore, increased fat in these hypercapnic subjects is related to this hormonal imbalance. The reason for the normocapnic group being without excess fat is less easy to explain in such terms, although the significantly raised levels of the adrenal androgen DHA in this group compared to either the controls or the hypercapnic patients may be a factor.

The failure to show raised serum LH levels in the presence of low serum testosterone suggests that primary testicular failure is unlikely. Taking the 16 study subjects together there was a significant correlation between the degree of hypoxia and the reduction in serum testosterone $(n=16$, $r=0.600, P<0.05)$ and also between the degree of hypercapnia and the reduction in testosterone values $(n=16, r=0.681, P<0.05)$. Probably, therefore, hypoxia induces these changes by reducing the release of either the gonadotrophin releasing hormone from the hypothalamus or LH from the pituitary. Dynamic testing would be required to confirm this hypothesis, but interestingly in this regard hypoxia reduces antidiuretic hormone production from the human posterior pituitary (Claybaugh et al, 1978).

Prolactin secretion from the pituitary is under the control of the inhibitory factor dopamine. Hyperprolactinaemia may arise in men for various reasons and may be associated with hypogonadism though rarely gynaecomastia (Thorner, 1976). The observed rise of serum prolactin in the three hypercapnic subjects in this study (table 3 ) does not seem to have been induced by pharmacological agents such as methyldopa, metoclopramide, or the phenothiazines that are known to have antidopaminergic actions (Thorner, 1976). Thus it is tempting to speculate that the observed hyperprolactinaemia in these three individuals also arose as a result of hypoxia-induced interruption of the hypothalamic-pituitary axis.

Early morning urinary aldosterone values were higher in the hypercapnic group, and this might reflect the hyperaldosteronism known to occur with respiratory failure. Hyperaldosteronism might account in part for the fluid retention and reduction in total body potassium known to occur in cor pulmonale (Campbell et al, 1975; Semple et al, 1978).

In conclusion, though caloric intake values estimated from dietary histories must be viewed with caution, we have shown no evident alteration in calorie intake or absorption of food to account for changes in body habitus in COAD. There do appear to be profound changes in anabolic steroid output and in prolactin production, apparently as a result of hypoxia affecting the hypothalamicpituitary axis. We postulate that such alterations in hormone production might be causally related to the fairly pronounced and contrasting changes in body habitus found in the two distinct clinical patterns in patients with chronic bronchitis and emphysema.

We thank Dr R J Cuthbert for permission to study his patients and the nursing and technical staff of the Nuclear Medicine Department, Southern General Hospital. We are grateful to Mrs Marion Cawood, Division of Steroid Endocrinology, University of Leeds, for urinary aldosterone determinations.

\section{References}

Campbell, R H A, Brand, H L, Cox, J R, and Howard, $P$ (1975). Body weight and body water in chronic cor pulmonale. Clinical Science and Molecular Medicine, 49, 323-335.

Cherniack, R M (1959). The oxygen consumption and efficiency of the respiratory muscles in health and emphysema. Journal of Clinical Investigation, 38, $494-499$.

Claybaugh, J R, Hansen, J E, and Wozwiak, D B (1978). Response of antidiuretic hormone to acute exposure to mild and severe hypoxia in man. Journal of Endocrinology, 77, 157-160.

Department of Health and Social Security (1969). Recommended Daily Intakes of Energy and Nutrients for UK. Report No 120. HMSO, London. Franks, S, Jacobs, H S, Martin, N, and Nabarro, 
J D N (1978). Hyperprolactinaemia and impotence. Clinical Endocrinology, 8, 277-287.

Greenwald, A J, Johnson, D S, Oskvig, R M, Aschenbrener, C A, and Randa, D C (1975). Alpha1-antitrypsin deficiency, emphysema, cirrhosis and intestinal mucosal atrophy. Journal of the American Medical Association, 231, 273-276.

Guerra-Garcia, R, Velasquez, A, and Coyotypa, J (1969). A test of endocrine gonadal function in men; urinary testosterone after injection of HCG. A different response of the high altitude native. Journal of Clinical Endocrinology and Metabolism, 29, 179182.

Hume, R, and Goldberg, A (1963). Actual and predicted-normal red-cell and plasma volumes in primary and secondary polycythaemia. Clinical Science, 26, 499-508.

Marmorston, J, Winer, J M, Hopkins, C E, and Stern, E (1966). Abnormalities in urinary hormone patterns in lung cancer and emphysema. Cancer, 19, 985-995.

McCance, R A, and Widdowson, E M (1960). The Composition of Foods. Medical Research Council, Special Report Series, No 297. HMSO, London.

Medical Research Council (1966). Committee on Research into Chronic Bronchitis. Questionnaire on Respiratory Symptoms. Medical Research Council, London.

Nadler, S B, Hidalgo, J V, and Bloch, T (1962). Prediction of blood volume in normal human adults. Surgery, 51, 224-232.
Pugh, L G C E (1962). Physiological and medicato aspects of the Himalayan scientific mountaineeringo expedition, 1960-1. British Medical Journal, 2, 621-क्ष

Semple, P d'A (1978). Alpha-1-antitrypsin deficiency and chest disease: a clinical and physiological study. Scottish Medical Journal, 23, 281-285.

Semple, P d'A, Watson, W S, Hume, R, and Suther-land, G R (1978). Potassium studies in chronic $\vec{\omega}$ obstructive airways diesase. Thorax, 33, 734-739.

Society of Actuaries (1959). Build and Blood Pressure $\vec{x}$ Study, vol 1, p 16. Chicago.

Stearns, E L, MacDonnell, J A, Kaufman, B J, Padua + R, Lucan, T S, Winter, J S D, and Fathan, C (1974)? Declining testicular function with age; hormonabo and clinical correlates. American Journal of Medi ${ }^{-}$ cine, 157, 761-766.

Thorner, M O (1976). Disorders of prolactin secretion.Journal of Clinical Pathology, 30, suppl 7, 36-41.

Thurlbeck, W M (1978). Diaphragm and body weight in emphysema. Thorax, 33, 483-487.

Wilson, N L, Wilson, R H L, and Farber, S M (1964). Nutrition in pulmonary emphysema. Journal of the American Dietetic Association, 45, 530-536.

Vandenbergh, E, van de Woestijne, K P, and Gyselen, 6 A (1967). Eight changes in terminal stages of chronic obstructive pulmonary disease. American Review of Respiratory Disease, 95, 556-566.

Requests for reprints to: $\operatorname{Dr} P$ d'A Semple, Chestö Clinic, Southern General Hospital, Glasgow G51. 